\title{
A Case Difficult to Diagnose in Adults: High Sinus Venous Atrial Septal Defect
}

\author{
Ozge Cetinarslan, Umit Yasar Sinan, Mehmet Serdar Kucukoglu \\ Department of Cardiology, Istanbul University, Institute of Cardiology, Istanbul, Turkey
}

\section{Abstract}

Sinus venous atrial septal defect (SVD) is highly difficult to diagnose because of its location. Below, we report a case of SVD which is misdiagnosed as pulmonary hypertension and anomalous pulmonary venous return. A 57 -year-old female patient was referred to congenital disease outpatient clinic of a tertiary center. She was admitted to the hospital with complaints of fatigue and exercise dyspnea which had started a year ago. She had transthoracic echocardiography (TTE) examination done in another hospital which showed dilated right heart chambers and pulmonary hypertension. She underwent transesophageal echocardiography (TEE) examination with the suspicion of atrial septal defect (ASD), but no defect was seen. As her symptoms persisted, we repeated the TTE and TEE examination in our center. TEE revealed $0.6 \mathrm{~cm}$ ASD on the upper side of the interatrial septum. All four pulmonary veins were draining into the left atrium. Right heart catheterization (RHC) confirmed the diagnosis. A left-to-right shunt was detected and localized by a significant step-up in blood oxygen saturation found between mid and upper segments of the right atrium. According to our TEE and RHC results, we planned the surgical closure of the defect. Sinus venous ASD is deficiency of the superior portion of atrial septum adjacent to superior vena cava. Diagnosis of SVD is often more difficult than other forms of ASD and may require special imaging such as TEE, magnetic resonance imaging, or computed tomographic scanning. In conclusion, cardiologists must be aware about the possibility of SVD patients who have unexplained exertional dyspnea and fatigue, dilated right atrium and ventricle, pulmonary hypertension, paradoxical embolism, or atrial arrhythmias in their respective populations.

Keywords: Adult congenital heart disease, atrial septal defect, sinus venous atrial septal defect, transesophageal echocardiography

\section{INTRODUCTION}

Atrial septal defect (ASD) is the most common congenital abnormality in adults characterized by defect on interatrial septum. The most common types of ASD include ostium primum ASD, ostium secundum ASD, and sinus venous ASD, respectively. Sinus venous atrial septal defect (SVD) is classified as high or low sinus venous type according to proximity to the superior vena cava (SVC) or inferior vena cava (IVC). SVD is highly difficult to diagnose because of its location. It requires surgical repair, and the outcome is much better if repair is done earlier.

Below, we report a case of SVD which is misdiagnosed as pulmonary hypertension and anomalous pulmonary venous return.

\section{Case Report}

A 57-year-old female patient was referred to congenital disease outpatient clinic of a tertiary center. She was admitted

\begin{tabular}{|c|c|}
\hline \multicolumn{2}{|c|}{ Access this article online } \\
\hline 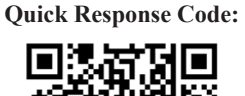 & $\begin{array}{l}\text { Website: } \\
\text { http://www.ijcva.com }\end{array}$ \\
\hline 1950 & $\begin{array}{l}\text { DOI: } \\
\text { 10.4103/IJCA.IJCA_4_18 }\end{array}$ \\
\hline
\end{tabular}

to the hospital with complaints of fatigue and exercise dyspnea which had started a year ago.

She had total thyroidectomy in her medical background, and she used 100 microgram oral levotirosin, daily. The patient's functional capacity was Grade III according to New York Heart Association functional classification. There was sinus rhythm and right bundle branch block on her electrocardiogram (ECG). Her laboratory tests were normal, and she walked $457 \mathrm{~m}$ on 6 min walk test [Figure 1].

She had transthoracic echocardiography (TTE) examination done in another hospital which showed dilated right heart chambers and pulmonary hypertension. She underwent

Address for correspondence: Dr. Ozge Cetinarslan, Department of Cardiology, Istanbul University, Institute of Cardiology, Istanbul, Turkey. E-mail: ozgecetinarslan@windowslive.com

This is an open access journal, and articles are distributed under the terms of the Creative Commons Attribution-NonCommercial-ShareAlike 4.0 License, which allows others to remix, tweak, and build upon the work non-commercially, as long as appropriate credit is given and the new creations are licensed under the identical terms.

For reprints contact: reprints@medknow.com

How to cite this article: Cetinarslan O, Sinan UY, Kucukoglu MS. A case difficult to diagnose in adults: High sinus venous atrial septal defect. Int J Cardiovasc Acad 2018;4:12-4. 
transesophageal echocardiography (TEE) examination with the suspicion of ASD, but no defect was seen. Magnetic resonance imaging (MRI) and cardiac computer tomography (CT) were planned to confirm the diagnosis of ASD. MRI revealed dilated pulmonary truncus, right atrium, and right ventricle, and CT showed abnormal venous connections [Figures 2 and 3].

As her symptoms persisted, we repeated the TTE and TEE examination in our center. TEE revealed $0.6 \mathrm{~cm}$ ASD on the upper side of interatrial septum. All four pulmonary veins were draining into the left atrium. Right heart catheterization (RHC) confirmed the diagnosis. A left-to-right shunt was detected and localized by a significant step-up in blood oxygen saturation found between mid and upper segments of the right atrium. Cardiac output, pulmonary output, pulmonary vascular resistance (PVR), and systemic vascular resistance (SVR) was calculated as $5.0 \mathrm{~L} / \mathrm{min}, 14.2 \mathrm{~L} / \mathrm{min}, 1.5$ Woods units, and 20.6 Wood units, respectively. Furthermore, Qp/Qs was calculated as 2.8 .

The patient's RHC results are appropriate to the closure of ASD. According to our TEE and RHC results, we planned the surgical closure of the defect.

\section{Discussion}

Sinus venous ASD is deficiency of the superior portion of atrial septum adjacent to SVC. ASDs account for about $10 \%-15 \%$ of all congenital cardiac anomalies and are the most common congenital cardiac lesion presenting in children and adults. ${ }^{[1]}$ SVD is relatively rare and is found in $2 \%-10 \%$ of patients with ASDs. Most of the patients are asymptomatic. Since many patients are asymptomatic at young age, the patients are diagnosed accidentally or when their symptoms become manifest at older ages. The patients most often present with congestive heart failure with pulmonary hypertension, atrial arrhythmias, right ventricular failure, or paradoxical embolization. Diagnosis of SVD is often more difficult than other forms of ASD and may require special imaging such as TEE, MRI, or CT scanning. ${ }^{[2]}$

Shub et al. demonstrated $100 \%$ of ostium primum and more than $90 \%$ of ostium secundum ASD but only $44 \%$ of SVD in their trial with 154 adults and children who underwent TTE. ${ }^{[3]}$ Kronzon et al. designed a similar study to establish value of TEE in SVDs. Forty-one adult patients from 18 to 81 years old with the clinical diagnosis of ASD were studied by TTE and TEE. In $8(20 \%)$ of 41 patients, the ASD was demonstrated by TEE and not by TTE. Six of the eight had a SVD; the other two patients had a secundum ASD (one of these two had a technically poor TTE and the other had a small ASD). TTE failed to demonstrate the SVD in $6(75 \%)$ of eight patients. ${ }^{[4]}$

Before correction of an ASD, an evaluation is made of the severity of the individual's pulmonary hypertension and whether it is reversible. Individuals with PVR more than 4.6 WU have increased mortality associated with closure of

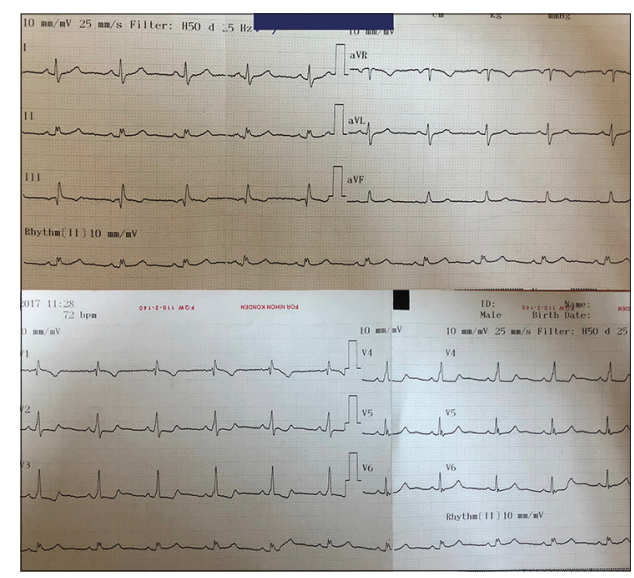

Figure 1: Electrocardiogram shows normal sinus rhythm

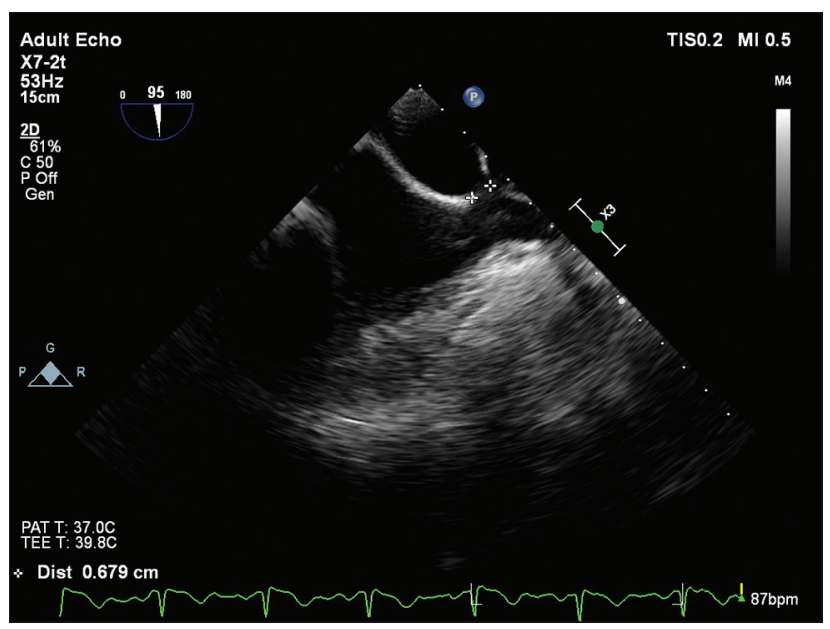

Figure 2: Transesophageal echocardiography shows $0.6 \mathrm{~cm}$ high sinus venous-type atrial septal defect

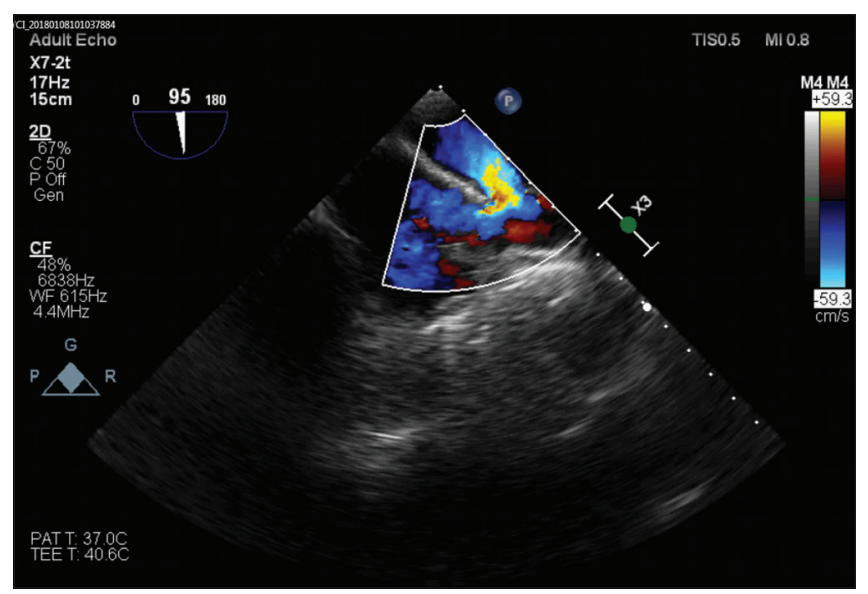

Figure 3: The color Doppler examination shows high sinus venous atrial septal defect

the ASD. While PVR is more than 2.3 WU but $<4.6 \mathrm{WU}$, closure of ASD appropriates if Qp: Qs is more than 1.5, PVR: $\operatorname{SVR}<2 / 3$, the defect is pretricuspid defect, and the patient is younger than 5 year old. 
ECG, also, may be helpful in diagnosing and differentiating the type of ASDs. Patients with ASD may have a prolonged PR interval. A first-degree heart block is probably due to the enlargement of the right atrium and increased distance of internodal conduction from the SA node to the AV node. ${ }^{[1]}$ In addition, the mean QRS axis is important in differentiating the secundum from the primum defect. True right axis deviation was present in $81 \%$ of the secundum defects and in none of the primum defects. Left axis deviation was present in $82 \%$ of the ostium primum defects and in none of the secundum defects. Following surgical closure of the secundum defect, the $\mathrm{R}^{\prime}$ usually decreases significantly within 4 months. There is often a normal $\mathrm{rSr}^{\prime}$ or $\mathrm{rS}$ in Lead $\mathrm{V} 1$ within 1 year after closure. If regression does not occur, then there is cause for doubt as to the complete closure of the defect, or the presence of irreversible pulmonary vascular changes may be suspected ${ }^{[5]}$ ECG of the patients with sinus venous ASD exhibits a left axis deviation of the P wave but not the QRS complex.

Both of percutaneous transcatheter closure or surgical closure strategies might be the treatment strategy. Catheter closure is only possible for the closure of secundum ASDs with a sufficient rim of tissue around the septal defect so that the closure device does not impinge on the SVC, IVC, or the tricuspid or mitral valves and aneurismal interatrial septum. Thus, the treatment of SVDs is surgical. All the complications must be treated with their optimal medical treatment according to their guidelines, respectively.

The prognosis is excellent for young patients who undergo repair of uncomplicated defects, particularly in the first 2 decades of their life. Repair delayed until the third decade of life is associated with a decrease in life expectancy ${ }^{[6]}$

\section{Conclusion}

Cardiologists must be aware about the possibility of SVD patients who have unexplained exertional dyspnea and fatigue, dilated right atrium and ventricle, pulmonary hypertension, paradoxical embolism, or atrial arrhythmias in their respective populations. If there is any suspicion about the diagnosis, all the imaging facilities such as ECG, TTE, $\mathrm{X}$-ray radiogram, TEE, CT scan, MRI, and RHC must be used to diagnose.

\section{Declaration of patient consent}

The authors certify that they have obtained all appropriate patient consent forms. In the form the patient(s) has/have given his/her/their consent for his/her/their images and other clinical information to be reported in the journal. The patients understand that their names and initials will not be published and due efforts will be made to conceal their identity, but anonymity cannot be guaranteed.

\section{Financial support and sponsorship}

Nil.

\section{Conflicts of interest}

There are no conflicts of interest.

\section{ReFERENCES}

1. Alpendurada F, Wage R, Mohiaddin R. Evaluation of a sinus venosus atrial septal defect by magnetic resonance: A case report. Rev Port Cardiol 2008;27:1317-21.

2. Sharma AK, Nath RK, Pandit N. A case of sinus venosus atrial septal defect misdiagnosed as primary pulmonary hypertension. Hellenic J Cardiol 2016;57:124-8.

3. Shub C, Dimopoulos IN, Seward JB, Callahan JA, Tancredi RG, Schattenberg TT, et al. Sensitivity of two-dimensional echocardiography in the direct visualization of atrial septal defect utilizing the subcostal approach: Experience with 154 patients. JAm Coll Cardiol 1983;2:127-35.

4. Kronzon I, Tunick PA, Freedberg RS, Trehan N, Rosenzweig BP, Schwinger ME, et al. Transesophageal echocardiography is superior to transthoracic echocardiography in the diagnosis of sinus venosus atrial septal defect. J Am Coll Cardiol 1991;17:537-42.

5. Pryor R, Woodwark GM, Blount SG Jr. Electrocardiographic changes in atrial septal defects: Ostium secundum defect versus ostium primum (endocardial cushion) defect. Am Heart J 1959;58:689-700.

6. Banka P, Bacha E, Powell AJ, Benavidez OJ, Geva T. Outcomes of inferior sinus venosus defect repair. J Thorac Cardiovasc Surg 2011;142:517-22. 